\title{
Mixed finite element for modelling interfaces
}

\author{
Salah Bouziane* — Hamoudi Bouzerd* — Mohamed Guenfoud** \\ * Department of Civil Engineering, University of Skikda, Skikda, Algeria \\ Bouziane21@yahoo.fr \\ Bib_ham@yahoo.fr \\ ** Laboratory of Civil Engineering and Hydraulic \\ University of Guelma \\ Guelma, Algeria \\ Gue2905m@yahoo.fr
}

ABSTRACT. A special finite element based on Reissner's mixed variational principle has been presented to model interface between two materials. The present element is a 7-node two dimensional mixed finite element with 5 displacement nodes and 2 stress nodes. The mixed interface finite element ensures the continuity of stress and displacement vectors at the interface on the coherent part and the discontinuity of this one on the cracked part. This element has been formulated starting from a parent element in a natural plane with an aim of modelling different types of interfaces with various orientations. This work is essentially devoted to the formulation of the interface element and the study of convergence and validation of this element. Results obtained from the present mixed interface element have been shown to be in good agreement with the analytical solutions.

RÉSUMÉ. Un élément spécial basé sur le principe variationnel mixte de Reissner est présenté pour modéliser l'interface entre deux matériaux. C'est un élément fini mixte bidimensionnel à 7 nœuds avec 5 nœuds déplacement et 2 nouds contrainte. Cet élément assure la continuité des vecteurs déplacement et contrainte sur la partie cohérente et la discontinuité de celle-ci sur la partie fissurée. L'élément proposé a été formulé à partir d'un élément de référence dans un plan naturel dans le but de modéliser les différents types d'interface avec leurs orientations. Ce travail a été consacré essentiellement à la formulation de l'élément d'interface et à l'étude de la convergence et de validation de ce dernier. Les résultats obtenus, avec l'élément d'interface présenté, montrent une bonne concordance avec les solutions analytiques.

KEYWORDS: mixed finite element, interface, Reissner's mixed variational principle, modelling. MOTS-CLÉS: élément fini mixte, interface, principe variationnel mixte de Reissner, modélisation.

DOI:10.3166/EJCM.18.155-175 @ 2009 Lavoisier, Paris 


\section{Introduction}

The disorders observed in an existing civil engineering structure, have generally their origin in local phenomena which reveal the weak points of this structure. These critical zones are located, on the one hand in the links between materials or interfaces, on the other hand in singularly formed areas such as cavities, angles and cracks, locations for strong stress concentrations.

In this paper, the mixed finite element method is used for the study of the interface in bimaterials. The mixed variational formulation has several advantages (Alturi et al., 1983; Mahapatra et al. 1988) over the conventional finite element formulations (specifically the displacement method), including direct evaluation of nodal stresses along with nodal displacements; improved accuracy of both displacements and stresses, and superior performance in capturing sharply changing stresses near stress-concentration zones; adequacy of lower-order elements (such as linear and bilinear elements), leading to elegant grids of discretization.

The mixed finite element method developed by Herrmann (1966) for plate bending analysis has been extended to plane elasticity problems by Mirza and Olson (1980). An exhaustive literature on mixed finite element models has been compiled by Noor (1983). Aivazzadeh (1984) developed a family of rectangular mixed interface element using Reissner's mixed variational principle. Habib (1989) presented various axisymmetric mixed element for studying bonded assemblies and laminate structure. Bichara (1990) and Sarhane-Bajbouj (1990) developed mixed finite elements for one or multi interfaces. Wu and Lin (1993) presented a two dimensional mixed finite element scheme based on a local high-order displacement model for the analysis of sandwich structure. Shi and Chen (1992) developed a three dimensional mixed finite element model based on global-local laminate variational model. Carrera (1996, 1998, 1999) also presented various mixed models based on Reissner's mixed variational principle. Ramtekkar et al. (2002) developed a three dimensional mixed finite element model using the minimum potential energy principle. This model has been used for the analysis of sandwich plates (2003). Desai and Ramtekkar (2002) presented a mixed finite element based on displacement theory satisfying fundamental elasticity relations. Bambole and Desai (2007) developed a two-dimensional hybrid-interface element based on the principle of minimum potential energy.

In this work a mixed finite element model has been presented using Reissner's mixed variational principle. The model takes into account the continuity of the interface on the coherent part (mechanical and geometrical continuity) and the discontinuity of this one on the cracked part (edge effect). This mixed finite element was developed by Bouzerd (1992) using a direct formulation: the shape functions of the displacement and stress fields are built directly starting from the real configuration of the element in a physical (x,y) plane. This element is employed only for the modelling of the rectilinear cracks (collinear), which limits its use. The nessicity to generalize its use for geometrical varieties of cracks and the need to 
study very important problems of cracking such as the crack kinking, returns the passage to the mapped elements necessary.

In the present paper, this element was reformulated starting from a parent element in a natural $(\xi, \eta)$ plane. This formulation presents, in addition to the simplification of calculations, the enormous advantage of modelling different types of interfaces with various orientations. This work is devoted primarily to the formulation of a mixed interface element and its validation. The accuracy of the element has been evaluated by comparing the numerical solution with an available analytical solution or numerical ones obtained from other finite elements.

\section{Formulation of the interface element}

The stages of construction of the proposed interface element are schematized on Figure 1. The RMQ-7 (Reissner Modified Quadrilateral) element is a quadrilateral mixed element with 7 nodes and 14 degrees of freedom (Bouzerd, 1992). Three of its sides are compatible with linear traditional elements and present a displacement node at each corner. The fourth side, in addition to its two displacement nodes of corner (node 1 and node 2), offers three additional nodes: a median node (node 5) and two intermediate nodes in the medium on each half-side (nodes 6 and 7), introducing the components of the stress vector along the interface.

The continuity of the displacement and stress vectors can be taken into account of the level on this particular side, which must be placed along the interface. In the cracked structures, the median node is associated to the point of crack; the two static nodes on both sides make it possible to meet two essential requirements of this situation, which are the free edge condition on the lips of the crack and the conditions of continuity along the coherent part.

At the beginning, we start with Reissner's mixed formulation with all displacements and all stresses like nodal variables to build the interface mixed element. There are thus surplus nodal variables. This formulation imposes too strong continuity, indeed the stress $\sigma_{11}$ appears among the variables considered in the Reissner variational functional, but does not appear among the interface stresses (separation stress $\sigma_{22}$ and shear stress $\sigma_{12}$ ); therefore we will eliminate this stress $\left(\sigma_{11}\right)$ in the formulation of the interface element.

\subsection{Reissner mixed element}

It is an element with four nodes and five degrees of freedom by node (all displacements and all stresses). The formulation of this element is based on Reissner's mixed variational principle (Reissner, 1950). 


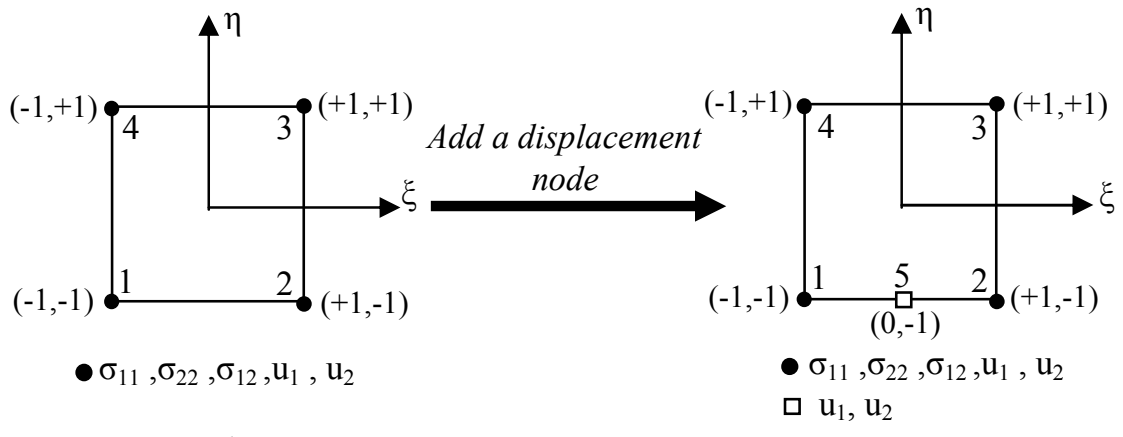

Reissner element

$$
R M Q-5 \text { element }
$$

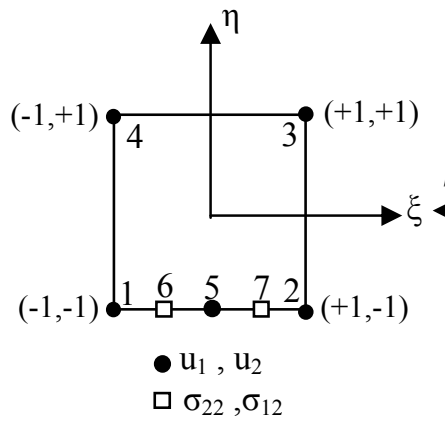

RMQ-7 element

\section{Static Condensation}

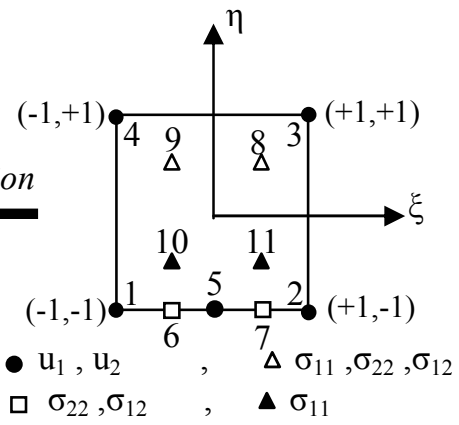

RMQ-11 element

Figure 1. Stages of construction of $R M Q-7$ element

The stress field in any point is written:

$$
\{\sigma\}=[\mathrm{M}]\{\tau\}
$$

where $[\mathrm{M}]$ is the matrix of interpolation functions for stresses.

and

$$
\{\sigma\}^{\mathrm{t}}=\left\{\sigma_{11}, \sigma_{22}, \sigma_{12}\right\}
$$


Further, the vector of nodal stresses and the matrix $[\mathrm{M}]$ can be stated respectively as

$$
\begin{aligned}
& \{\tau\}^{t}=\left\{\sigma_{11}^{1}, \sigma_{22}^{1}, \sigma_{12}^{1}, \sigma_{11}^{2}, \sigma_{22}^{2}, \sigma_{12}^{2}, \sigma_{11}^{3}, \sigma_{22}^{3}, \sigma_{12}^{3}, \sigma_{11}^{4}, \sigma_{22}^{4}, \sigma_{12}^{4}\right\} \\
& {[M]=\left[\begin{array}{cccccccccccc}
M_{1} & 0 & 0 & M_{2} & 0 & 0 & M_{3} & 0 & 0 & M_{4} & 0 & 0 \\
0 & M_{1} 0 & 0 & M_{2} 0 & 0 & M_{3} & 0 & 0 & M_{4} & 0 \\
0 & 0 & M_{1} & 0 & 0 & M_{2} & 0 & 0 & M_{3} & 0 & 0 & M_{4}
\end{array}\right]}
\end{aligned}
$$

The shape functions are given by:

$$
\begin{array}{ll}
\mathrm{M}_{1}=\frac{1}{4}(1-\xi)(1-\eta), & \mathrm{M}_{2}=\frac{1}{4}(1+\xi)(1-\eta) \\
\mathrm{M}_{3}=\frac{1}{4}(1+\xi)(1+\eta), & \mathrm{M}_{4}=\frac{1}{4}(1-\xi)(1+\eta)
\end{array}
$$

The displacement field is expressed by:

$$
\{\mathrm{u}\}=[\mathrm{N}]\{\mathrm{q}\}
$$

where $[\mathrm{N}]$ is the matrix of interpolation functions for displacements.

and

$$
\{u\}^{t}=\left\{u_{1}, u_{2}\right\}
$$

Further, the vector of nodal displacements and $[\mathrm{N}]$ can be stated respectively as

$$
\begin{aligned}
& \{\mathrm{q}\}^{\mathrm{t}}=\left\{\mathrm{u}_{1}^{1}, \mathrm{u}_{2}^{1}, \mathrm{u}_{1}^{2}, \mathrm{u}_{2}^{2}, \mathrm{u}_{1}^{3}, \mathrm{u}_{2}^{3}, \mathrm{u}_{1}^{4}, \mathrm{u}_{2}^{4}\right\} \\
& {[\mathrm{N}]=\left[\begin{array}{llllllll}
\mathrm{N}_{1} & 0 & \mathrm{~N}_{2} & 0 & \mathrm{~N}_{3} & 0 & \mathrm{~N}_{4} & 0 \\
0 & \mathrm{~N}_{1} & 0 & \mathrm{~N}_{2} & 0 & \mathrm{~N}_{3} & 0 & \mathrm{~N}_{4}
\end{array}\right]}
\end{aligned}
$$

The shape functions are

$$
\mathrm{N}_{1}=\frac{1}{4}(1-\xi)(1-\eta) \quad, \quad \mathrm{N}_{2}=\frac{1}{4}(1+\xi)(1-\eta)
$$




$$
\mathrm{N}_{3}=\frac{1}{4}(1+\xi)(1+\eta) \quad, \quad \mathrm{N}_{4}=\frac{1}{4}(1-\xi)(1+\eta)
$$

The strains are obtainable from the strain-displacement equations in usual manner:

$$
\{\varepsilon\}=[B]\{\mathrm{q}\}
$$

where $[\mathrm{B}]$ is the strain-displacement transformation matrix.

and

$$
\{\varepsilon\}^{t}=\left\{\varepsilon_{11}, \varepsilon_{22}, \varepsilon_{12}\right\}
$$

The nodal approximation of the displacement and stress fields is expressed by:

$$
\left\{\begin{array}{c}
\{\sigma\} \\
\{\varepsilon\}
\end{array}\right\}=\left[\begin{array}{ll}
{[\mathrm{M}]} & {[0]} \\
{[0]} & {[\mathrm{B}]}
\end{array}\right]\left\{\begin{array}{l}
\{\tau\} \\
\{\mathrm{q}\}
\end{array}\right\}
$$

Substitution of the expression [13] in the Reissner variational functional leads to the discretized form of the functional R (Bichara, 1990):

$$
R=\frac{1}{2}\left\{\begin{array}{c}
\{\tau\} \\
\{\mathrm{q}\}
\end{array}\right\}^{\mathrm{t}}\left[\mathrm{K}_{\mathrm{e}}\right]\left\{\begin{array}{c}
\{\tau\} \\
\{\mathrm{q}\}
\end{array}\right\}-\left\{\begin{array}{c}
\{\tau\} \\
\{\mathrm{q}\}
\end{array}\right\}^{\mathrm{t}}\left\{\begin{array}{c}
\left\{\mathrm{F}_{\sigma}^{\mathrm{e}}\right\} \\
\left\{\mathrm{F}_{\mathrm{u}}^{\mathrm{e}}\right\}
\end{array}\right\}
$$

where $\left[\mathrm{K}_{\mathrm{e}}\right]$ is the element matrix defined by:

$$
\left[\mathrm{K}_{\mathrm{e}}\right]=\left[\begin{array}{ll}
{\left[\mathrm{K}_{\sigma \sigma}\right]} & {\left[\mathrm{K}_{\sigma u}\right]} \\
{\left[\mathrm{K}_{\sigma u}\right]^{\mathrm{t}}} & {[0]}
\end{array}\right]
$$

Here $\quad\left[\mathrm{K}_{\sigma \sigma}\right]=-\mathrm{e} \int_{\mathrm{A}^{\mathrm{c}}}[\mathrm{M}]^{\mathrm{t}}[\mathrm{S}][\mathrm{M}] \mathrm{dA}^{\mathrm{e}}$

and $\quad\left[\mathrm{K}_{\sigma \mathrm{u}}\right]=\mathrm{e} \int_{\mathrm{A}^{\mathrm{e}}}[\mathrm{M}]^{\mathrm{t}}[\mathrm{B}] \mathrm{dA} \mathrm{A}^{\mathrm{e}}$

where: $\mathrm{e}$ is the thickness, $[\mathrm{S}]$ is the compliance matrix and $\mathrm{A}^{\mathrm{e}}$ is the element area.

The element equivalent forces vector is composed of two vectors: one corresponds to displacements $\left\{F_{u}^{\mathrm{e}}\right\}$; the second vector corresponds to the stresses, $\left\{\mathrm{F}_{\sigma}^{\mathrm{e}}\right\}$ is equal to zero in the absence of initial strains. 
$\left\{\mathrm{F}_{\mathrm{u}}^{\mathrm{e}}\right\}$ and $\left\{\mathrm{F}_{\sigma}^{\mathrm{e}}\right\}$ are given by

$$
\begin{aligned}
& \left\{\mathrm{F}_{\mathrm{u}}^{\mathrm{e}}\right\}=\mathrm{e} \int[\mathrm{N}]^{\mathrm{t}}\left\{\overline{\mathrm{T}}^{\mathrm{e}}\right\} \mathrm{dL} \mathrm{L}_{\sigma} \\
& \left\{\mathrm{F}_{\sigma}^{\mathrm{e}}\right\}=\{0\}
\end{aligned}
$$

where $\mathrm{L}_{\sigma}$ : part of the contour $\mathrm{L}$ on which the tractions are prescribed,

$[\mathrm{N}]$ : matrix of interpolation functions for displacements,

$\left\{\overline{\mathrm{T}}^{\mathrm{e}}\right\}$ : prescribed tractions on $\mathrm{L}_{\sigma}$.

\subsection{Construction of the parent element RMQ-5}

The RMQ-5 element is obtained by adding a displacement node to the Reissner mixed element. It is a mixed element with 5 nodes and 22 degrees of freedom. It has a side (associate with the interface) presenting three nodes, the medium node (displacement node) characterizes the bottom of the crack in the final version of the element. The RMQ-5 and the Reissner elements present the same static behaviour. The stress field is expressed by the same shape functions $M_{i}$.

The element displacement component is approximated by:

$$
\{\mathrm{u}\}=[\mathrm{N}]\{\mathrm{q}\}
$$

where

$$
\{q\}^{t}=\left\{u_{1}^{1}, u_{2}^{1}, u_{1}^{2}, u_{2}^{2}, u_{1}^{3}, u_{2}^{3}, u_{1}^{4}, u_{2}^{4}, u_{1}^{5}, u_{2}^{5}\right\}
$$

and

$$
[\mathrm{N}]=\left[\begin{array}{cccccccccc}
\mathrm{N}_{1} & 0 & \mathrm{~N}_{2} & 0 & \mathrm{~N}_{3} & 0 & \mathrm{~N}_{4} & 0 & \mathrm{~N}_{5} & 0 \\
0 & \mathrm{~N}_{1} & 0 & \mathrm{~N}_{2} & 0 & \mathrm{~N}_{3} & 0 & \mathrm{~N}_{4} & 0 & \mathrm{~N}_{5}
\end{array}\right]
$$

New shape functions are:

$$
\begin{array}{ll}
\mathrm{N}_{1}=-\frac{1}{4}(1-\xi)(1-\eta) \xi \quad, \quad \mathrm{N}_{2}=\frac{1}{4}(1+\xi)(1-\eta) \xi \quad, \quad \mathrm{N}_{3}=\frac{1}{4}(1+\xi)(1+\eta) \\
\mathrm{N}_{4}=\frac{1}{4}(1-\xi)(1+\eta), \quad \mathrm{N}_{5}=\frac{1}{2}\left(1-\xi^{2}\right)(1-\eta)
\end{array}
$$




\subsection{Construction of the RMQ-11 element}

The RMQ-11 element is obtained starting from the parent element RMQ-5 by relocalisation (Verchery, 1987) of certain variables inside the element and by displacement of static nodal unknown of the corners towards the side itself. It is an element with 11 nodes and 22 degrees of freedom. The displacements nodes are still unchanged either by number sum, or in position. Do the elements RMQ-5 and RMQ-11 present the same shape functions.

The generalized approximation of the element stress field is written:

$$
\sigma(\xi, \eta)=\{\mathrm{P}(\xi, \eta)\} \mathrm{a}\}
$$

where polynomial base of the element is

$$
\{\mathrm{P}(\xi, \eta)\}=\left\{\begin{array}{llll}
1 & \xi & \eta & \xi \eta
\end{array}\right\}
$$

and $\{\mathrm{a}\}$ are the generalized variables.

We have:

$$
\{\tau\}=\left[\mathrm{P}_{\mathrm{n}}\right]\{\mathrm{a}\}
$$

where $\left[\mathrm{P}_{\mathrm{n}}\right]$ is the nodal matrix.

Thus the approximation of the stress field according to the nodal variables $\{\tau\}$ is:

$$
\left.\sigma(\xi, \eta)=\{\mathrm{P}(\xi, \eta)\} \mathrm{P}_{\mathrm{n}}\right]^{-1}\{\tau\}=[\mathrm{M}]\{\tau\}
$$

The element stress $\sigma_{11}$ is approximated by

$$
\left.\sigma_{11}(\xi, \eta)=\{\mathrm{P}(\xi, \eta)\}\left[\mathrm{P}_{\mathrm{n} 11}\right]^{-1}\left\{\begin{array}{l}
\sigma_{11}^{8} \\
\sigma_{11}^{9} \\
\sigma_{11}^{10} \\
\sigma_{11}^{11}
\end{array}\right\}=\left[\mathrm{M}_{11}\right]\right\}\left[\begin{array}{l}
\sigma_{11}^{8} \\
\sigma_{11}^{9} \\
\sigma_{11}^{10} \\
\sigma_{11}^{11}
\end{array}\right\}
$$

where $\left[\mathrm{P}_{n 11}\right]=\left[\begin{array}{rrrr}1 & +0.5 & +0.5 & +0.25 \\ 1 & -0.5 & +0.5 & -0.25 \\ 1 & -0.5 & -0.5 & +0.25 \\ 1 & +0.5 & -0.5 & -0.25\end{array}\right]$ and $\left[\mathrm{M}_{11}\right]=\left\{\begin{array}{llll}1 & \xi & \eta & \xi \eta\end{array}\right\}\left[\mathrm{P}_{\mathrm{n} 11}\right]^{-1}$ 
In the configuration of Figure 1, the shape functions are given by:

$$
\begin{array}{lll}
\mathrm{M}_{11}^{8}=\frac{1}{4}(1+2 \xi)(1+2 \eta) & , & \mathrm{M}_{11}^{9}=\frac{1}{4}(1-2 \xi)(1+2 \eta) \\
\mathrm{M}_{11}^{10}=\frac{1}{4}(1-2 \xi)(1-2 \eta) & \mathrm{M}_{11}^{11}=\frac{1}{4}(1+2 \xi)(1-2 \eta)
\end{array}
$$

The element stress $\sigma_{22}$ and $\sigma_{12}$ are given as follows:

$$
\sigma_{\mathrm{i} 2}(\xi, \eta)=\{\mathrm{P}(\xi, \eta)\}\left[\mathrm{P}_{\mathrm{ni} 2}\right]^{-1}\left\{\begin{array}{l}
\sigma_{\mathrm{i} 2}^{6} \\
\sigma_{\mathrm{i} 2}^{7} \\
\sigma_{\mathrm{i} 2}^{8} \\
\sigma_{\mathrm{i} 2}^{9}
\end{array}\right\}=\left[\mathrm{M}_{\mathrm{i} 2}\right]\left\{\begin{array}{c}
\sigma_{\mathrm{i} 2}^{6} \\
\sigma_{\mathrm{i} 2}^{7} \\
\sigma_{\mathrm{i} 2}^{8} \\
\sigma_{\mathrm{i} 2}^{9}
\end{array}\right\} \quad, \mathrm{i}=1,2
$$

where $\left[\mathrm{P}_{\text {ni2 }}\right]=\left[\begin{array}{cccc}1 & -0.5 & -1 & +0.5 \\ 1 & +0.5 & -1 & -0.5 \\ 1 & +0.5 & +0.5 & +0.5 \\ 1 & -0.5 & +0.5 & -0.25\end{array}\right]$ and $\left[\mathrm{M}_{\mathrm{i} 2}\right]=\left\{\begin{array}{llll}1 & \xi & \eta & \xi \eta\end{array}\right\}\left[\mathrm{P}_{\mathrm{ni} 2}\right]^{-1}$

In the configuration of Figure 1, the shape functions are given by:

$$
\begin{array}{lll}
\mathrm{M}_{\mathrm{i} 2}^{6}=\frac{1}{6}(1-2 \xi)(1-2 \eta) & , & \mathrm{M}_{\mathrm{i} 2}^{7}=\frac{1}{6}(1+2 \xi)(1-2 \eta) \\
\mathrm{M}_{\mathrm{i} 2}^{8}=\frac{1}{3}(1+2 \xi)(1+\eta) & \mathrm{M}_{\mathrm{i} 2}^{9}=\frac{1}{3}(1-2 \xi)(1+\eta)
\end{array}
$$

Finally the stress field is given by:

$$
\sigma(\xi, \eta)=\left\{\begin{array}{l}
\sigma_{11} \\
\sigma_{22} \\
\sigma_{12}
\end{array}\right\}=[\mathrm{M}]\{\tau\}
$$

where

$$
[\mathrm{M}]=\left[\begin{array}{ccc}
\left\{\mathrm{M}_{11}\right\} & \{0\} & \{0\} \\
\{0\} & \left\{\mathrm{M}_{22}\right\} & \{0\} \\
\{0\} & \{0\} & \left\{\mathrm{M}_{12}\right\}
\end{array}\right]
$$


and

$$
\{\tau\}^{\mathrm{t}}=\left\{\sigma_{11}^{8}, \sigma_{11}^{9}, \sigma_{11}^{10}, \sigma_{11}^{11}, \sigma_{22}^{6}, \sigma_{22}^{7}, \sigma_{22}^{8}, \sigma_{22}^{9}, \sigma_{12}^{6}, \sigma_{12}^{7}, \sigma_{12}^{8}, \sigma_{12}^{9}\right\}
$$

The element stiffness matrix is written in the form given by the expressions [15], [16] and [17]. This matrix can be evaluated by Gauss numerical integration scheme, with four points $(2 \times 2)$ on the element.

\subsection{Construction of the RMQ-7 element}

The four internal nodes of RMQ-11 element complicate the setting operation of data, and increase the size of the half-width band during the assembly, which causes an increase in the computing time. The method used for condensation of the internal degrees of freedom to contour is related to the general concept of reduction of the size of an equations system per elimination of a certain number of variables. Gallagher (1976) used this type of procedure in structural analysis. The static condensation procedure leads to the following reduced elementary matrix:

$$
\left[\mathrm{K}_{\mathrm{e}}\right]=\left[\begin{array}{ll}
{\left[\mathrm{K}_{\sigma \sigma}\right]^{*}} & {\left[\mathrm{~K}_{\sigma \mathrm{u}}\right]^{*}} \\
{\left[\mathrm{~K}_{\mathrm{u \sigma}}\right]^{*}} & {\left[\mathrm{~K}_{\mathrm{uu}}\right]^{*}}
\end{array}\right]
$$

where

$$
\begin{aligned}
& {\left[\mathrm{K}_{\sigma \sigma}\right]^{*}=\left[\mathrm{K}_{\sigma \sigma}\right]_{\mathrm{c}}-\left[\mathrm{K}_{\sigma \sigma}\right]_{\mathrm{ci}}\left[\mathrm{K}_{\sigma \sigma}\right]_{\mathrm{i}}^{-1}\left[\mathrm{~K}_{\sigma \sigma}\right]_{\mathrm{ci}}^{\mathrm{t}}} \\
& {\left[\mathrm{K}_{\sigma \mathrm{u}}\right]^{*}=\left[\mathrm{K}_{\sigma \mathrm{u}}\right]_{\mathrm{c}}-\left[\mathrm{K}_{\sigma \mathrm{u}}\right]_{\mathrm{i}}\left[\mathrm{K}_{\sigma \mathrm{u}}\right]_{\mathrm{i}}^{-1}\left[\mathrm{~K}_{\sigma \mathrm{u}}\right]_{\mathrm{i}}^{\mathrm{t}}} \\
& {\left[\mathrm{K}_{\mathrm{u \sigma}}\right]^{*}=\left[\mathrm{K}_{\sigma \mathrm{u}}\right]_{\mathrm{i}}^{* \mathrm{t}}}
\end{aligned}
$$

and

$$
\left[\mathrm{K}_{\mathrm{uu}}\right]^{*}=-\left[\mathrm{K}_{\sigma \mathrm{u}}\right]_{\mathrm{i}}\left[\mathrm{K}_{\sigma \sigma}\right]_{\mathrm{i}}^{-1}\left[\mathrm{~K}_{\sigma \mathrm{u}}\right]_{\mathrm{i}}^{\mathrm{t}}
$$

Here $\mathrm{i}$ indicate the intern static nodal variables and $\mathrm{c}$ the static nodal variable of contour. 
The reduced stiffness matrix has a block $\left[\mathrm{K}_{\mathrm{uu}}\right]^{*}$ semi-definite positive, contrary to the non reduced form where this block is always equal to zero. The procedure of condensation enables us to obtain the RMQ-7 element having only 7 nodes with two degrees of freedom by node. The nodes 6 and 7 are stress nodes with the variables $\sigma_{22}, \sigma_{12}$ and the remains are displacement nodes.

\section{Numerical examples}

\subsection{Eigenvalue analysis of the element matrix}

Mirza and Olson (1980) studied the convergence of the mixed element in the energy sense by defining an energy product and the associated energy norm directly in a selected space. The restriction imposed on the order of polynomials used for approximating displacements and stresses is similar to what is known as the consistency condition. It has found that in mixed finite element formulation, a violation of the restriction imposed on the order of the polynomial for approximating the dependent variables can lead to the mechanism resulting in non-unique solution (Mahapatra et al., 1988). An eigenvalue analysis for various combinations of polynomials for displacements and stresses would explain such mechanism. Thus eigenvalues furnish an important test of element quality, where the number of negative eigenvalues should always correspond to the number of stress degrees of freedom. The eigenvalue is equal to zero when the corresponding degree of freedom represents rigid body motion.

A study on the nature and number of eigenvalues of the element matrix has been undertaken and is reported in Table 1.

Table 1. Eigenvalues for various elements

\begin{tabular}{|c|c|c|c|c|c|c|}
\hline \multirow{2}{*}{$\begin{array}{l}\text { Type of } \\
\text { element }\end{array}$} & \multicolumn{3}{|c|}{ Degree of Freedom } & \multicolumn{2}{|c|}{ Eigenvalues } & \multirow{2}{*}{$\begin{array}{l}\text { Composition of the } \\
\text { eigenvectors }\end{array}$} \\
\hline & Displacement & Stress & Total & Sign & Num. & \\
\hline $\begin{array}{l}\text { Displacement } \\
\text { element } \\
\text { ( } 4 \text { nodes })\end{array}$ & 8 & 0 & 8 & $\begin{array}{l}(-) \\
(0) \\
(+)\end{array}$ & $\begin{array}{l}- \\
3 \\
5\end{array}$ & $\begin{array}{c}- \\
\varepsilon_{\mathrm{ij}}=0 \\
\mathrm{u}_{1}, \mathrm{u}_{2} \text { bilinear }\end{array}$ \\
\hline $\begin{array}{l}\text { Reissner } \\
\text { mixed } \\
\text { element } \\
\text { (4 nodes) }\end{array}$ & 8 & 12 & 20 & $\begin{array}{l}(-) \\
(0) \\
(+)\end{array}$ & $\begin{array}{l}12 \\
3 \\
5\end{array}$ & $\begin{array}{l}\mathrm{u}, \sigma \text { bilinear } \\
\varepsilon_{\mathrm{ij}}=0, \sigma_{\mathrm{ij}}=0 \\
\mathrm{u}, \sigma \text { bilinear }\end{array}$ \\
\hline $\begin{array}{l}\text { Present mixed } \\
\text { element } \\
\text { (RMQ-7) }\end{array}$ & 10 & 4 & 14 & $\begin{array}{l}(-) \\
(0) \\
(+)\end{array}$ & $\begin{array}{l}4 \\
3 \\
7\end{array}$ & $\begin{array}{c}\sigma \text { bilinear, u quadratic } \\
\varepsilon_{\mathrm{ij}}=0, \sigma_{\mathrm{ij}}=0 \\
\sigma \text { bilinear, u quadratic }\end{array}$ \\
\hline
\end{tabular}


The result of evaluation of eigenvalues, which shows the correct number and appropriate signs including the expected number of zero eigenvalue, testifies the correctness of the formulation. Table 1 show that the RMQ-7 element checks well the criterion of representation of rigid modes.

\subsection{Tests of representation of homogeneous states}

The present mixed element will be studied in two loading cases generating of the homogeneous stress and strain states. These elementary tests constitute a preliminary study of validity of our interface element. An element (or elements) will be subjected to tests of uniform traction and pure shear with the following characteristics: $E=1 \mathrm{~N} / \mathrm{mm}^{2}, v=0.25$ and loading density $p=1 \mathrm{~N} / \mathrm{mm}^{2}$. Figures 9 and 10, in appendix, show the different case of loading for one element or two elements. Tables 2, 3, 4 and 5 present numerical results and theoretical values in the case of only one element or two assembled elements.

Table 2. Comparison of results by the present element and theory for one element (uniform traction)

\begin{tabular}{|c|c|c|c|c|c|c|c|c|}
\hline \multirow{4}{*}{} & \multicolumn{7}{|c|}{ Name of evaluated parameter at the node } \\
\cline { 2 - 9 } & \multicolumn{2}{|c|}{$\mathrm{u}_{1}(\mathrm{~mm})$} & \multicolumn{2}{c|}{$\mathrm{u}_{2}(\mathrm{~mm})$} & \multicolumn{2}{c|}{$\sigma_{22}\left(\mathrm{~N} / \mathrm{mm}^{2}\right)$} & \multicolumn{2}{|c|}{$\sigma_{12}\left(\mathrm{~N} / \mathrm{mm}^{2}\right)$} \\
\cline { 2 - 9 } & $\begin{array}{c}\text { Case 1 } \\
\text { Node 5 }\end{array}$ & $\begin{array}{c}\text { Case 2 } \\
\text { Node 2 }\end{array}$ & $\begin{array}{c}\text { Case 1 } \\
\text { Node 5 }\end{array}$ & $\begin{array}{c}\text { Case 2 } \\
\text { Node 2 }\end{array}$ & $\begin{array}{c}\text { Case 1 } \\
\text { Nodes } \\
6\end{array}$ & $\begin{array}{c}\text { Case 2 } \\
\text { Node 7 }\end{array}$ & $\begin{array}{c}\text { Case 1 } \\
\text { Node 6 }\end{array}$ & $\begin{array}{c}\text { Case 2 } \\
\text { Node 7 }\end{array}$ \\
\hline RMQ-7 & 0.50 & 1.00 & 0.00 & -0.25 & 0.00 & 0.00 & 0.00 & 0.00 \\
\hline Theory & 0.50 & 1.00 & 0.00 & -0.25 & 0.00 & 0.00 & 0.00 & 0.00 \\
\hline
\end{tabular}

Table 3. Comparison of results by the present element and theory for one element (pure shear)

\begin{tabular}{|l|c|c|c|c|c|c|c|c|}
\hline \multirow{1}{*}{} & \multicolumn{8}{|c|}{ Name of evaluated parameter at the node } \\
\cline { 2 - 9 } & \multicolumn{2}{|c|}{$\mathrm{u}_{1}(\mathrm{~mm})$} & \multicolumn{2}{c|}{$\mathrm{u}_{2}(\mathrm{~mm})$} & $\sigma_{22}\left(\mathrm{~N} / \mathrm{mm}^{2}\right)$ & \multicolumn{2}{|c|}{$\sigma_{12}\left(\mathrm{~N} / \mathrm{mm}^{2}\right)$} \\
\cline { 2 - 9 } & $\begin{array}{c}\text { Case 1 } \\
\text { Node } \\
5\end{array}$ & $\begin{array}{c}\text { Case 2 } \\
\text { Node } \\
2\end{array}$ & $\begin{array}{c}\text { Case 1 } \\
\text { Node } \\
5\end{array}$ & $\begin{array}{c}\text { Case 2 } \\
\text { Node } \\
2\end{array}$ & $\begin{array}{c}\text { Case 1 } \\
\text { Node } \\
6\end{array}$ & $\begin{array}{c}\text { Case 2 } \\
\text { Node } \\
7\end{array}$ & $\begin{array}{c}\text { Case 1 } \\
\text { Node } \\
6\end{array}$ & $\begin{array}{c}\text { Case 2 } \\
\text { Node } \\
7\end{array}$ \\
\hline RMQ-7 & 0.00 & 0.00 & 1.25 & 2.50 & 0.00 & 0.00 & 1.00 & 1.00 \\
\hline Theory & 0.00 & 0.00 & 1.25 & 2.50 & 0.00 & 0.00 & 1.00 & 1.00 \\
\hline
\end{tabular}

It can easily be seen that all numerical tests results of representation of homogeneous states check the theoretical values. 
Checking this criterion is necessary owing to the fact that when the mesh is refined, the state of strain and stress is practically constant by element. It is then desirable that the approximation functions can represent this state.

Table 4. Comparison of results by the present element and theory for two assembled elements (uniform traction)

\begin{tabular}{|l|c|c|c|c|c|c|c|c|}
\hline \multirow{1}{*}{} & \multicolumn{8}{|c|}{ Name of evaluated parameter at the node } \\
\cline { 2 - 9 } & \multicolumn{2}{|c|}{$\mathrm{u}_{1}(\mathrm{~mm})$} & \multicolumn{2}{c|}{$\mathrm{u}_{2}(\mathrm{~mm})$} & $\sigma_{22}\left(\mathrm{~N} / \mathrm{mm}^{2}\right)$ & \multicolumn{2}{|c|}{$\sigma_{12}\left(\mathrm{~N} / \mathrm{mm}^{2}\right)$} \\
\cline { 2 - 9 } & $\begin{array}{c}\text { Case 1 } \\
\text { Node } \\
9\end{array}$ & $\begin{array}{c}\text { Case 2 } \\
\text { Node } \\
\text { Case 1 }\end{array}$ & $\begin{array}{c}\text { Node } \\
9\end{array}$ & $\begin{array}{c}\text { Case 2 } \\
\text { Node 7 }\end{array}$ & $\begin{array}{c}\text { Case 1 } \\
\text { Node } \\
5\end{array}$ & $\begin{array}{c}\text { Case 2 } \\
\text { Node } \\
6\end{array}$ & $\begin{array}{c}\text { Case 1 } \\
\text { Node } \\
5\end{array}$ & $\begin{array}{c}\text { Case 2 } \\
\text { Node } \\
6\end{array}$ \\
\hline RMQ-7 & 0.75 & 1.00 & 0.00 & -0.125 & 0.00 & 0.00 & 0.00 & 0.00 \\
\hline Theory & 0.75 & 1.00 & 0.00 & -0.125 & 0.00 & 0.00 & 0.00 & 0.00 \\
\hline
\end{tabular}

Table 5. Comparison of results by the present element and theory for two assembled elements (pure shear)

\begin{tabular}{|l|c|c|c|c|c|c|c|c|}
\hline \multirow{4}{*}{} & \multicolumn{8}{|c|}{ Name of evaluated parameter at the node } \\
\cline { 2 - 9 } & \multicolumn{2}{|c|}{$\mathrm{u}_{1}(\mathrm{~mm})$} & \multicolumn{2}{c|}{$\mathrm{u}_{2}(\mathrm{~mm})$} & $\sigma_{22}\left(\mathrm{~N} / \mathrm{mm}^{2}\right)$ & $\sigma_{12}\left(\mathrm{~N} / \mathrm{mm}^{2}\right)$ \\
\cline { 2 - 9 } & Case 1 & Case 2 & Case 1 & Case 2 & Case 1 & Case 2 & Case 1 & Case 2 \\
& Node 9 & Node 7 & Node 9 & Node 7 & Nodes 5 & Node 6 & Node 5 & Node 6 \\
\hline RMQ-7 & 0.00 & 0.00 & 1.875 & 2.50 & 0.00 & 0.00 & 1.00 & 1.00 \\
\hline Theory & 0.00 & 0.00 & 1.875 & 2.50 & 0.00 & 0.00 & 1.00 & 1.00 \\
\hline
\end{tabular}

\subsection{Convergence test of a plane beam}

In order to evaluate the validity and the credibility of the present element, a study of the convergence on a cantilever beam in bending is carried out. A cantilever beam, with dimensions and loading as shown in Figure 2, is subjected to two types of loading. The first type of loading corresponds to a uniform distribution of transversal load distributed on the end of the beam by respecting energy equivalence. The second type of loading corresponds to a pure test of bending.

This problem has been solved by the present mixed element (for various meshes) to compare our result with the literature result, so as to gain additional confidence in the workability of the present element. Table 6 presents a comparison of deflections at the point $\mathrm{A}$.

Table 6 shows the good results obtained with the present mixed element compared with those of the analytical solution. Indeed, with a number of degrees of freedom definitely lower than those retained in the other comparative elements, excellent results are obtained. 


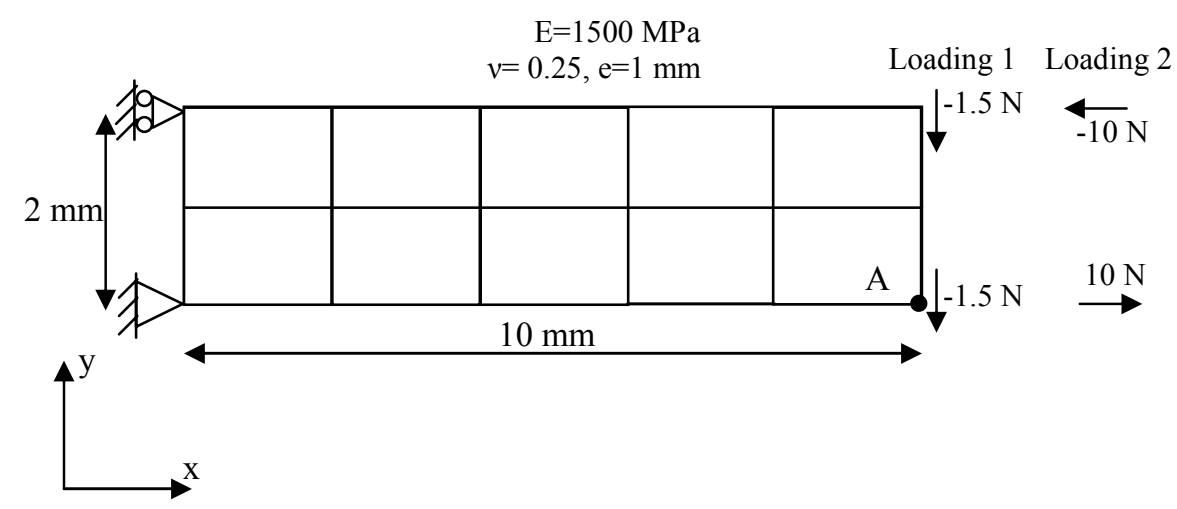

Figure 2. Test of cantilever beam-Mesh

Table 6. Comparison of deflection in a cantilever problem solved by various elements

\begin{tabular}{|l|c|c|c|}
\hline \multirow{2}{*}{ Element type } & \multirow{2}{*}{ Number of degrees of freedom } & \multicolumn{2}{c|}{ Deflection at point A (mm) } \\
\cline { 3 - 4 } & & Loading 1 & Loading 2 \\
\hline Displacement (4 nodes) & 728 & 0.961 & 0.922 \\
\hline Reissner(4 nodes) & 1431 & 1.023 & 0.998 \\
\hline Quad-1 Bichara (1990) & 498 & 1.029 & 1.000 \\
\hline Present mixed element & 150 & 1.000 & 0.976 \\
\hline Classical theory & - & 1.000 & 1.000 \\
\hline Timoshenko theory & - & 1.030 & 1.000 \\
\hline
\end{tabular}

To see the convergence rapidity of the deflection at point A, several meshes are used. All the results obtained are reported in Table 7 according to the number of elements and degrees of freedom.

Table 7. Deflection in a cantilever problem solved by various meshes

\begin{tabular}{|c|c|c|c|}
\hline \multirow{2}{*}{$\begin{array}{c}\text { Number of } \\
\text { elements }\end{array}$} & $\begin{array}{c}\text { Number of degrees } \\
\text { of freedom }\end{array}$ & \multicolumn{2}{|c|}{ Deflection at point A (mm) } \\
\cline { 3 - 4 } & 30 & 0.501 & Loading 2 \\
\hline 4 & 66 & 0.913 & 0.577 \\
\hline 10 & 126 & 0.999 & 0.901 \\
\hline 20 & 138 & 0.999 & 0.974 \\
\hline 22 & 150 & 1.000 & 0.975 \\
\hline 24 & & & 0.976 \\
\hline
\end{tabular}


Figure 3 represents the convergence of the deflection. It is noted that the interface mixed element converges very quickly for a number relatively low of degrees of freedom.

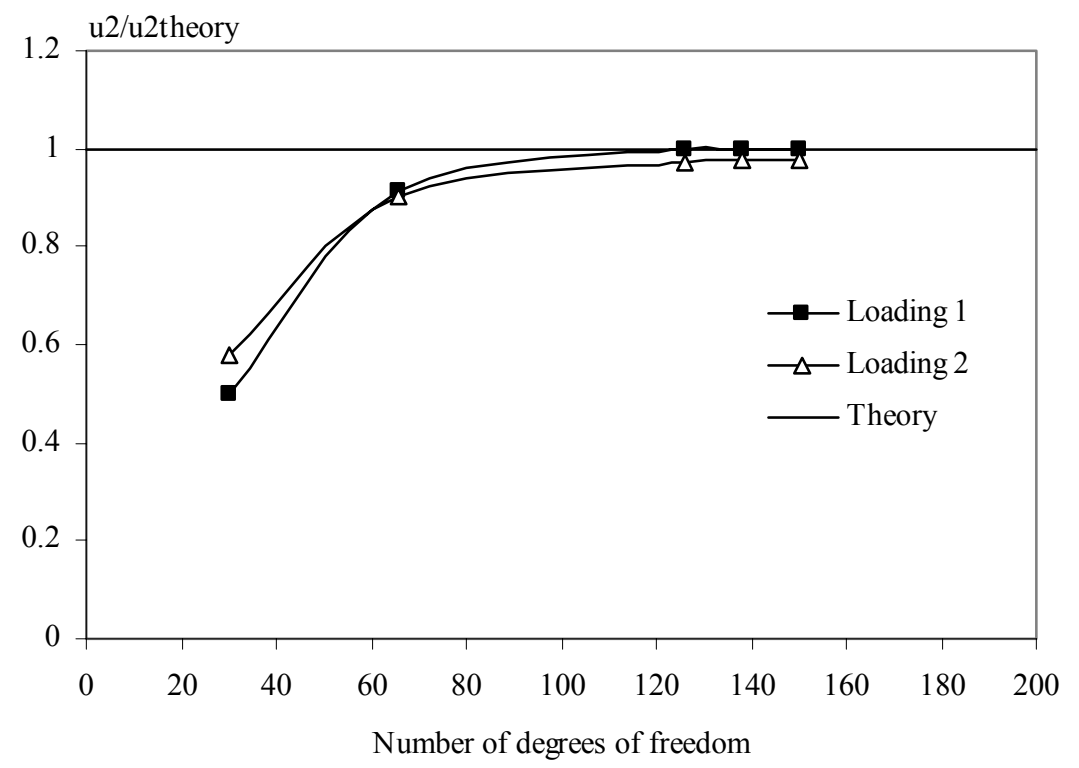

Figure 3. Convergence of deflection in a cantilever beam

\subsection{Cantilever beam with distorted elements}

To highlight the effectiveness of the proposed element to model interfaces in any direction, we have taken the same example (cantilever beam) using different meshes with distorted elements (any quadrangular elements).

Mesh 1 (Figure 4): It contains 20 elements (126 dof) with elements of interface oriented in $\Delta y(\Delta y=5 \%$ and $10 \%$ of the horizontal dimension of the element).

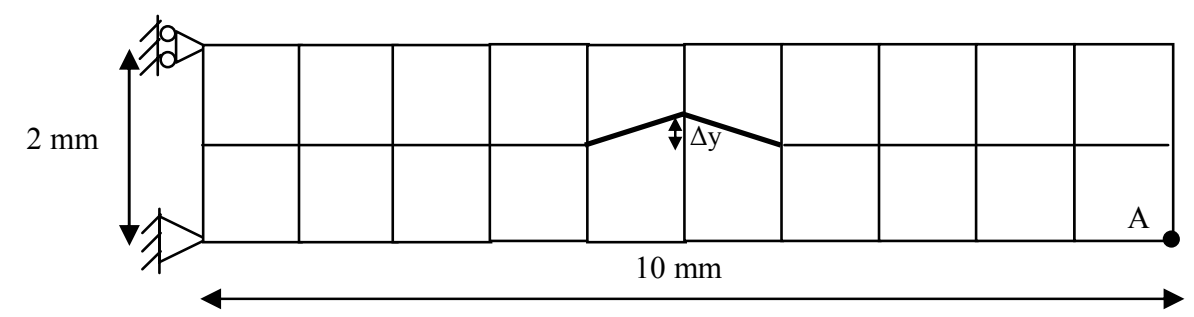

Figure 4. Mesh 1 
Mesh 2 (Figure 5): It contains 20 elements (126 dof) with elements of curvilinear interface ( $\Delta y=5 \%$ and $10 \%$ of the horizontal dimension of element).

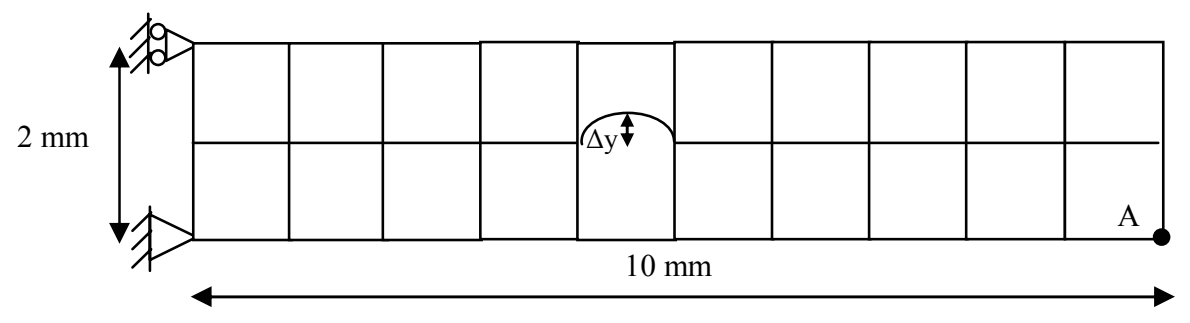

Figure 5. Mesh 2

Tables 8 and 9 show the results of the deflection to point A for the different types of meshes.

Table 8. Deflection in a cantilever problem - Mesh 1

\begin{tabular}{|c|c|c|c|}
\hline \multirow{2}{*}{} & \multirow{2}{*}{$\Delta \mathrm{y}(\%)$} & \multicolumn{2}{|c|}{ Deflection at point A (mm) } \\
\cline { 3 - 4 } & & Loading 1 & Loading 2 \\
\hline \multirow{2}{*}{ Present element (RMQ 7) } & 5 & 0,982 & 0,959 \\
\cline { 2 - 4 } & 10 & 0,935 & 0,918 \\
\hline Classical theory & - & 1,000 & 1,000 \\
\hline Timoshenko theory & - & 1,030 & 1,000 \\
\hline
\end{tabular}

Table 9. Deflection in a cantilever problem - Mesh 2

\begin{tabular}{|c|c|c|c|}
\hline \multirow{2}{*}{} & \multirow{2}{*}{$\Delta \mathrm{y}(\%)$} & \multicolumn{2}{|c|}{ Deflection at point A (mm) } \\
\cline { 3 - 4 } & & Loading 1 & Loading 2 \\
\hline \multirow{2}{*}{ Present element (RMQ 7) } & 5 & 0,962 & 0,943 \\
\cline { 2 - 4 } & 10 & 0,872 & 0,867 \\
\hline Classical theory & - & 1,000 & 1,000 \\
\hline Timoshenko theory & - & 1,030 & 1,000 \\
\hline
\end{tabular}

Tables 8 and 9 show a good accuracy of results compared to the analytical solution. This confirms the capacity and efficiency of the element to model interfaces in any direction. 


\subsection{Sandwich beam}

Simply supported sandwich beam has been considered. This beam presents three isotropic layers and presenting coherent interfaces. A sandwich beam, with dimensions and material properties as shown in Figure 6, is subjected to uniform load and the interest is primarily centered on the study of transverse shear stresses and the deflection.

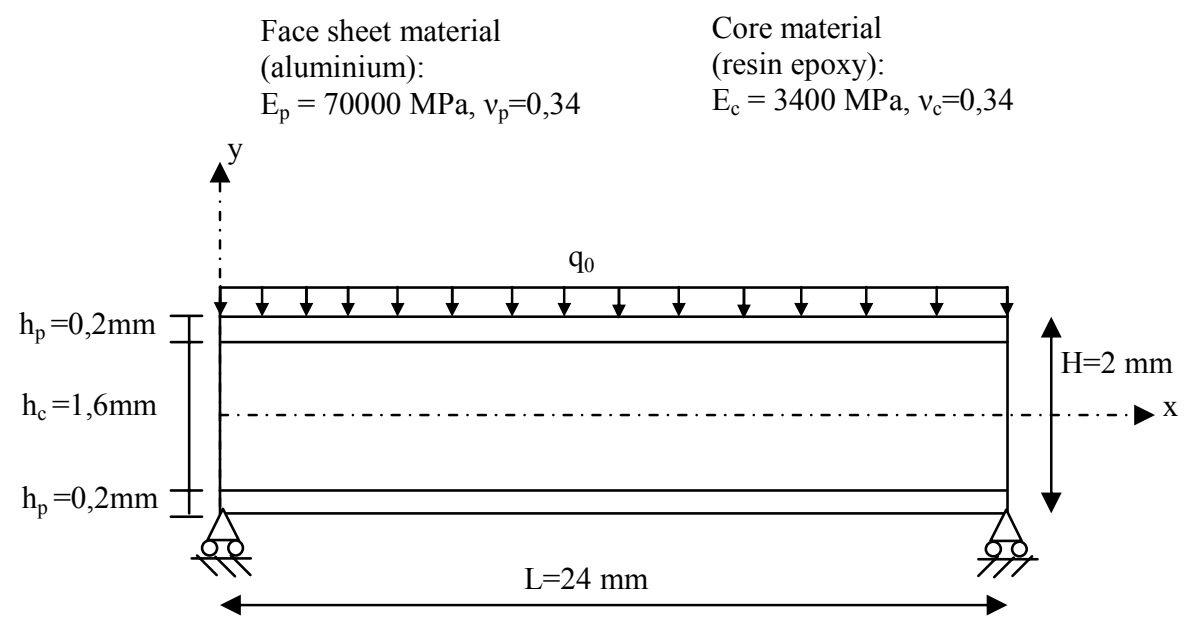

Figure 6. Sandwich beam analyzed

To see the convergence rapidity of the transverse shear and deflection several meshes are used. Results obtained trough the present mixed element for various numbers of degrees of freedom are tabulated in Tables 10 and 11 where they have been compared with the elastic solutions given by Pagano (1970). Table 10 shows the deflection values obtained at $\mathrm{x}=\mathrm{L} / 2$ according to the number of degrees of freedom. Variation of transverse shear at $\mathrm{x}=\mathrm{L} / 4$ has been presented in Table 11. It can be seen that the results from the present mixed element are in very good agreement with the elasticity solution (Pagano, 1970).

Table 10. Deflection in a sandwich beam at $x=L / 2$ solved by various meshes

\begin{tabular}{|c|c|c|}
\hline Element type & Number of degree of freedom & Deflection $\mathrm{u}_{2}(\mathrm{~mm})$ \\
\hline \multirow{3}{*}{ Present mixed element } & 32 & -0.105 \\
\cline { 2 - 3 } & 98 & -0.200 \\
\cline { 2 - 3 } & 402 & -0.209 \\
\hline Pagano (1970) & - & -0.208 \\
\hline
\end{tabular}


172 European Journal of Computational Mechanics. Volume 18 - No. 2/2009

Table 11. Transverse shear in a sandwich beam at $x=L / 4$ solved by various meshes

\begin{tabular}{|c|c|c|c|c|}
\hline \multirow{2}{*}{ Element type } & \multirow{2}{*}{$\begin{array}{c}\text { Number of } \\
\text { degree of } \\
\text { freedom }\end{array}$} & \multicolumn{3}{|c|}{ Transverse shear $\sigma_{12}(\mathrm{MPa})$} \\
\hline & & $y=-h_{c} / 2$ & $y=0$ & $\mathrm{y}=\mathrm{h}_{\mathrm{c}} / 2$ \\
\hline \multirow{3}{*}{$\begin{array}{l}\text { Present mixed } \\
\text { element }\end{array}$} & 32 & -3.026 & - & -3.001 \\
\hline & 98 & -3.135 & - & -3.258 \\
\hline & 402 & -3.197 & -3.314 & -3.184 \\
\hline Pagano (1970) & - & -3.159 & -3.431 & -3.158 \\
\hline
\end{tabular}

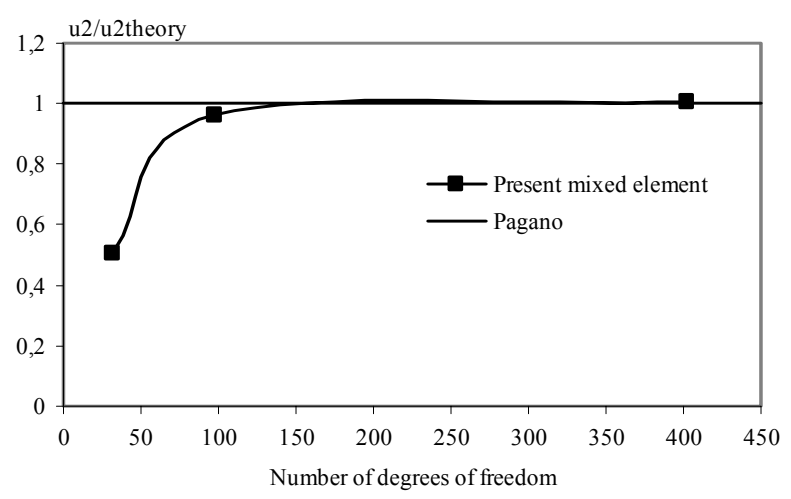

Figure 7. Convergence of deflection at $x=L / 2$

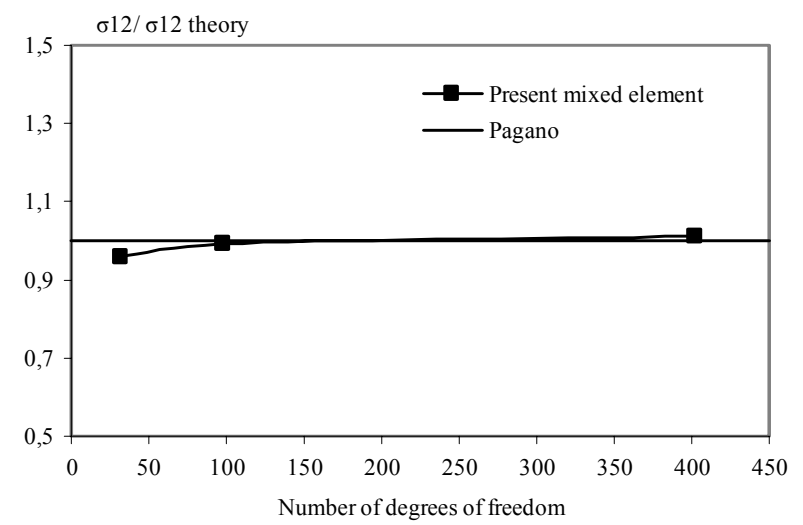

Figure 8. Convergence of transverse shear at $x=L / 4\left(y=-h_{c} / 2\right)$ 
Figures 7 and 8 show the variation of the deflection and the transverse shear respectively with the number of degrees of freedom. It appears that the mixed interface element converges very quickly for a number relatively low of degrees of freedom.

\section{Conclusion}

The mixed finite element method is used to derive a special interface element. The mixed variational formulation proves to be a very accurate method of numerical analysis for the evaluation of displacements and stresses of boundary value problem. This formulation is considerably modulated by the requirement of a discretization grid with a lower number of nodal points, which can easily confer accuracy on a par with that achieved by displacement method with a finer mesh or higher-order elements.

The present mixed element was built in order to answer as well as possible the conditions of continuity of displacement and stress vectors in the coherent part, and of discontinuity of displacements and effect edge on the cracked part. In the formulation of this element, we used Reissner's mixed variational principle to build the parent element. The mixed interface finite element is obtained by successively exploiting the technique of relocalisation and the static condensation procedure. The formulation starting from a parent element in a natural plane present the enormous advantage of modelling different types of interfaces with various orientations. This work was especially centred on the formulation aspect, the convergence and validation of the present interface element through the study of simple's examples. Economy of analysis is achieved when the present elements are included with a relatively smaller mesh and present sufficiently accurate results. The accuracy of the element has been evaluated by comparing the numerical solution with an available analytical solution or numerical ones obtained from others finite elements. Results obtained from the present mixed interface element have been shown to be in good agreement with the analytical solutions.

\section{References}

Aivazzadeh S., Eléments finis d'interface. Application aux assemblages collés et structures stratifiées, Thèse de docteur-ingénieur, Université de Technologie de Compiègne, 1984.

Alturi S. N., S. Gallagher S., Zienkiewicz O. C., Hybrid and mixed finite element method, New York, John Willey and Sons, 1983.

Bambole A. N., Desai Y. M., "Hybrid-interface finite element for laminated composite and sandwich beams", Finite Elements in Analysis and Design, 43, 2007, p. 1023-1036.

Bichara M., Formulation d'éléments d'interface. Application aux assemblages collés, Thèse de doctorat, Université Paris VI, 1990.

Bouzerd H., Elément fini mixte pour interface cohérente ou fissurée, Thèse de doctorat, Université de Claude Bernard, Lyon I, 1992. 
Carrera E., " $\mathrm{C}^{0}$ Reissner-Mindlin multilayered plate elements including zig-zag and interlaminar stress continuity", Int. J. Num. Meth. Engng., 39, 1996, p. 1797-1820.

Carrera E. "Mixed layer-wise models for multilayered plates analysis", Compos. Struct., 43, 1998, p. 57-70.

Carrera E., "Transverse normal stress effects in multilayered plates", ASME J. Appl. Mech., 66, 1999, p. 1004-1011.

Desai Y. M., Ramtekkar G. Y., "Mixed finite element model for laminated composite beams", Struct. Eng. Mech., 13, 2002, p. 261-276.

Gallagher R. H., Introduction aux éléments finis, Paris, Pluralis (traduction française), 1976.

Habib M., Eléments finis axisymétriques d'interface pour l'analyse des structures stratifiées et des assemblages collés, Thèse de doctorat, Université de Claude Bernard, Lyon I, 1989.

Herrmann L. R., "A bending analysis for plates", Proc. Conf. Matrix Methods in Structural Mechanics, AFFDL-TR-66-80, 1966, p. 577-604.

Mahapatra R. C., Dasgupta S. P., "The mixed finite element method in elastic and elastoplastic axisymmetric problems", Comput. Struct., 30, 1988, p. 1047-1065.

Mirza F. A., Olson M. D., "The mixed finite element method in plane elasticity", Int. J. Num. Meth. Engng., vol. 15, 1980, p. 273-289.

Noor A. K., Multified (mixed and hybrid) finite elements models, State of the art surveys in finite element technology, ASME, chapter 5, 1983, p. 127-162.

Pagano N. J., "Exact solutions for rectangular bidimensionnal composite and sandwich plates", Journal of Composite Materials, vol. 4, 1970, p. 20-35.

Ramtekkar G. S., Desai Y. M., Shah A. H., "Mixed finite element model for thick composite laminated plates", Mech. Adv. Mater. Struct., 9, 2002, p. 133-156.

Ramtekkar G. S., Desai Y. M., Shah A. H., "Application of three-dimensional mixed finite element model to the flexure of sandwich plate", Comput. Struct., 81, 2003, p. 2183-2198.

Reissner E., "On a variational theorem of elasticity", Journal of Mathematics and Physics, vol. 29,1950 , p. 90-95.

Sarhan-Bajbouj A., Eléments finis d'interface pour le calcul des structures hétérogènes, Thèse de doctorat, Université de Claude Bernard, Lyon I, 1990.

Shi Y. B., Chen H. R., “A mixed finite element for interlaminar stress computation”, Compos. Strut., 20, 1992, p. 127-136.

Verchery G., Méthodes numériques de calcul des champs de contraintes dans les matériaux hétérogènes, Calcul des Structures et Intelligence Artificielle, Fouet J. M., Ladeveze P., Ohayon R., vol. 1, Paris, Pluralis, 1987, p. 7-21.

Wu C. P., Lin C. C., "Analysis of sandwich plates using mixed finite element”, Compos. Strut. 25, 1993, p. 397-405. 


\section{Appendix}
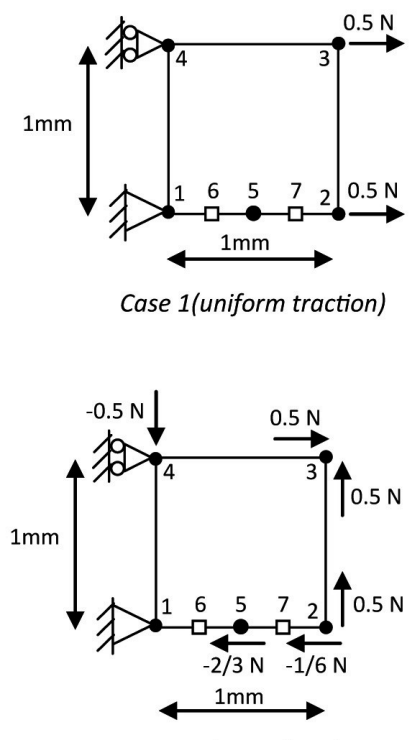

Case 1(pure shear)

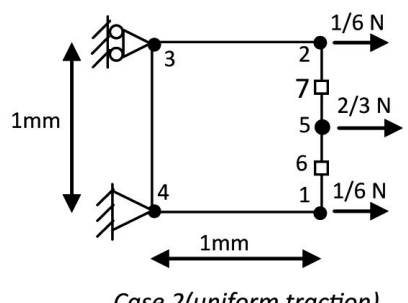

Case 2(uniform traction)

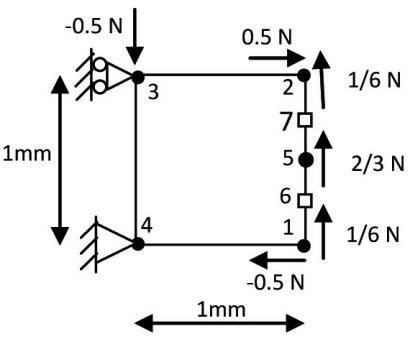

Case 2(pure shear)

Figure 9. Test on one element
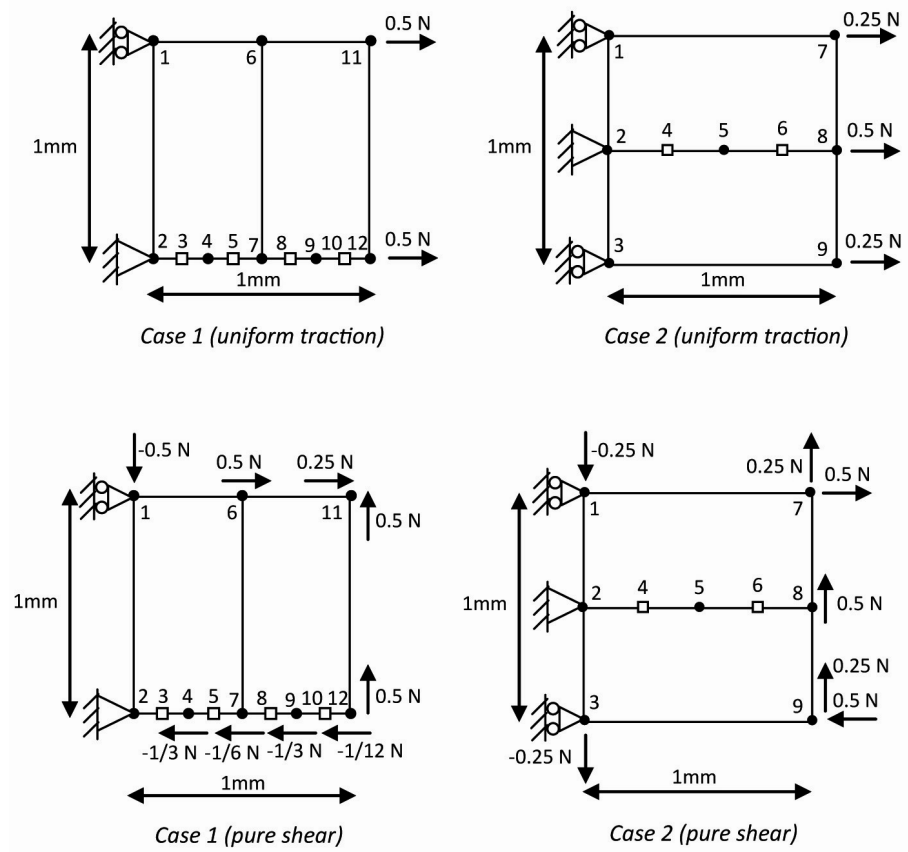

Figure 10. Test on two assembled elements 
